\title{
Remarks on Environmental Stewardship in the U.S. Virgin Islands
}

\author{
Senator Adlah Donastorg *
}

\section{INTRODUCTION}

A pleasant good afternoon. It is always a pleasure to be a part of and explore different things. I would like to thank you and this event for having me here this afternoon. As a politician, I do not have a legal background. I have a business background. Of course, when I was first elected to public office, one of the things I immediately did was spend a lot of time on the legal end because I felt there was a special art and technique in drafting legislation.

If I may, I will go into just a brief history of my experiences and the office that I held here in the U.S. Virgin Islands. I was the liaison to the United States Congress for three consecutive terms, whereby I interacted with Congress quite often. In fact, I became the most unpopular Senator among my colleagues because one of the first initiatives I pushed was to reduce the size of the Virgin Islands Legislature from fifteen to nine. You see, we are governed by what you call the Organic Act of the Virgin Islands. The Organic Act is our local constitution, consistent with the United States Constitution. In order for us to effectuate any changes in the Organic Act, we must pursue and request Congress to make those changes to the Organic Act. In my many pursuits, such as dealing with lifting caps on Medicare and Medicaid funding, there have been some serious challenges. I also chaired the Committee on Environmental Protection for three consecutive terms. I also chaired the Committee on Government Operations for one term. For one term, I chaired the most powerful committee in the Virgin Islands: the Committee on Finance that controls the budget of the Virgin Islands. In addition to that, and the final note when it comes to talking about my background, I just ran for Governor of the Virgin Islands and was unsuccessful in November 2006. But as Michael Jordan once said, "I'll be back."

Senator Adlah Donastorg represents the U.S. Virgin Islands. These remarks were originally given at the University of Kansas School of Law on November 9, 2007, as part of the Kansas Law Review's Biolaw Symposium. 
Despite my business background, they often describe me as being the environmental Senator in the Virgin Islands. I have been the maverick, the sponsor, and the one who has drafted most of the major environmental pieces of legislation in Virgin Islands history: the Clean Air Act, the Clean Water Act, oil recycling, oil disposal, all solid waste, sewage waste, a write-on to the antiquities bill, and of course, landmark legislation the Senate recently adopted while I served-the Territorial Park System that I take great pride in.

\section{ENVIRONMENTAL CRISES AFFECTING THE U.S. VIRGIN ISLANDS}

I would like to start once again by saying good afternoon. It is such an honor to be here. I have been asked to address you this afternoon. It seems that the national media has finally taken quite a change on a serious issue. We do not talk much about climate change in the Virgin Islands. If you were to ask the average Virgin Islander about climate change, they probably would not even respond to you. You see, environmental issues were on the backburner when I first assumed office some twelve years ago. Although coming from a business background, because of my love for the environment, I recognized that we needed a spokesperson in the institution who can truly champion the things that seek to protect our environment. I am trying to champion those pieces of legislation because, for most Virgin Islanders, environmental degradation and overdevelopment has hit much closer to home. I was even tagged and described as the pit-bull Senator because of the way I championed the initiatives and tried to get my point across. When I embarked on a political career, my best friend embarked on a different profession, that of sewage disposal. And he said to me once: "You know, there's a driver for every seat. Somebody's got to do it, but you have to take pride in what you do." He turned around and came up with this slogan for his line of business of sewage disposal: he is number one in the number two business. Somebody's got to do it. So, the lesson I learned from my friend is that somebody in the U.S. Virgin Islands has to champion these important, but overlooked, environmental issues.

\section{A. Growing Public Awareness Due to Dangerous and Unmanaged Landfills}

We do not talk much about planet change, as I indicated, in the Virgin Islands. But for most Virgin Islanders, environmental degradation means a lot to them. Overdevelopment, especially on the island of St. Thomas, has hit an alarming level. There is not too much 
open space that exists on the Virgin Islands, or on St. Thomas, right now. The U.S. Virgin Islands consist of four different islands - St. Thomas, St. Croix, St. John, and Water Island, which was a recent adoption. Small island systems are especially fragile. Everything goes into our water and land is very, very limited. In the last few years, we have experienced a serious and all-too-tangible decline in our quality of life.

Today I would like to tell you a little bit about my experiences as a lawmaker in the U.S. Virgin Islands. Even years ago, when I first took office, only a handful of people talked about environmental issues. I would never venture to say that Virgin Islanders were ignorant; it is just that there were other issues that were a priority to a majority of Virgin Islanders. You know as a politician - and I often like to refer to myself as a statesman, not a politician, to make a distinction and hope that people look at me as an exception to that rule-I refused to use the term "educate" the public. I often use the term "enlighten." There is a distinction for a lot of Virgin Islanders when you talk about educating and enlightening, and I prefer to use the word "enlighten." I think it is far more effective. Most Virgin Islanders were more concerned about economic opportunities than ecology, but that changed following Hurricane Marilyn. I am quite sure many of you heard about this hurricane terrorizing the islands, and in fact, it hit closer to home when New Orleans had the experience not too long ago of a hurricane devastating that area.

Nonetheless, following Hurricane Marilyn in 1995, we experienced what was likely our first modern environmental crisis. The landfill erupted in a toxic cloud of smoke, impacting thousands of residents. We had to appeal to the Centers for Disease Control and Prevention (CDC) and the Environmental Protection Agency (EPA) to ask for federal funding so that our jurisdiction could address those vexing problems that confronted us. We learned that there were several acres of methane fires raging on the ground. Because the landfill had been so mismanaged, particularly after the hurricane, the entire island of St. Thomas was at risk from a major fire or explosion. The Army Corps of Engineers-and I must thank the Army Corps of Engineers, who came in at my requestbasically told us that the landfill was a toxic soup of chemicals, with things like empty propane tanks and waste oil mixed in with regular garbage, all resting on these acres of raging fires. For one to live the experience, it was like a volcanic reaction. The residents would walk in a landfill and see smoke coming out of the earth. Of course, the landfill was open to anyone who wanted to go there on the landfill physically and dispose of their garbage. There was also a great deal of improperly disposed medical waste. We had a terrible experience where there were 
kids running around in the landfill with syringes, some of the syringes still had the needle attached to it. This was a very, very dangerous situation. So as an elected official, I took the bull by the horns and I decided that this was the ideal opportunity to bring environmental issues from the back burner to the front burner because it was something that was close to the hearts of the residents and people of the Virgin Islands whose kids were being exposed to this type of stuff.

On an island the size of St. Thomas, there is nowhere to run or no way to evacuate some 60,000 people. Ash and smoke was present across the entire island from at least two major fires. Young students from a nearby school and residents of the public housing community were most at risk. No one was immune from the potential dangers. We had adjacent hotels and several other residential areas on the other side of the island that were actually affected by what was taking place. Those living and working near the landfill began complaining of all kinds of illnesses. In fact, when we checked the statistics in the hospital to see the number of individuals experiencing respiratory problems or who had cancer, there was in fact a significant increase.

Yet, our local government did not act. I made dozens of personal inspections and held several senate committee meetings on the landfill crisis. I wrote what seemed like hundreds of letters, imploring the EPA, Army Corps, and the CDC for assistance. For quite some time, I was known as the "dump Senator." That was another title they gave me, but I took that as a compliment. We learned a lot through this process - that our landfill was poorly managed and that it lacked even the most rudimentary security. We learned that it was one of the few places in the United States where people could dispose of their garbage for free. We learned that it was dozens of years past its capacity. And we learned that toxic chemicals and metals were seeping from the landfill and into our largest mangrove lagoon, and winding up in our fish, lobster, crabs, and conch. For those of you who know of seafood in the Virgin Islands, you know what conch is and what lobster is. Well, everyone knows what lobster is. But I am quite sure that you do not know what is called the whelk. It is another form of seafood.

I was able to organize with the local environmental advocacy group called E.A.S.T., and we were eventually able to get our government to act to get the landfill fires under control. We received some federal assistance and even a short-term study by the agency for toxic substance and disease registry. I have to thank them, and I would thank them every time I am afforded the opportunity.

We still do not know what the long term health effects will be for Virgin Islanders, living in close proximity to this landfill. Like I said, we 
learned a lot, but perhaps the most valuable lesson was that we, as a community, needed to pay much greater attention to our natural resources. During this period, I developed a philosophy that stuck with me, which I can summarize with a single phrase that I have heard: "Clean air and clean water are basic human rights." During my five terms in office, I did my best to keep these issues at the forefront and I sponsored some significant legislation to include local versions of the Clean Air and Clean Water Acts.

\section{B. Overdevelopment and the Loss of Public Green Space}

Our most serious problem now is overdevelopment. I think islands are often overlooked when discussing overdevelopment, especially when you look at Dubai and the rapid development that has taken place there, but our most serious problem now is overdevelopment in St. Thomas. We not only have a huge problem with non-point source pollution killing our reefs and fish, but we have suffered a huge blow to our quality of life, with fewer and fewer places for us to hike, fish, camp, and relax with our families. As in many other desirable parts of the U.S., there was, and to some extent continues to be, a huge building boom in the Virgin Islands. Our boom was partially spurred by a tragically flawed and extremely generous tax exemption program for investors. We have a $100 \%$ tax exemption program in the Virgin Islands - a tax shelter that is quite encouraging and has lured many investors to our shores with major development. While I have been criticized over the years as being a Senator or elected official that was anti-business, I am not anti-business. I am pro-business and pro-development — but I strongly encourage planned development. That is what I am more concerned aboutmaking sure that we have mechanisms in place such as a comprehensive land and water use plan that seeks to protect the green spaces that should not be developed.

Beachfront properties, in particular, were quickly bought up. Many of these properties, though privately owned, have been traditionally used as public beaches. Other such properties in less successful areas were left previously undeveloped and home to a great deal of wildlife, as well as acting as a buffer between land and sea. What took place in just a few years on St. Thomas remains almost unbelievable. I say St. Thomas because the situations on St. John and St. Croix are far different-also somewhat vexing, but completely different. It is certainly fair to say that the struggle continues. For example, in one situation, several tracts of beachfront land were purchased by a wealthy family and access was blocked by a razor wire and armed guards. This is a beach where 
families swam and fished for generations, and I myself personally enjoyed swimming on that beach as a student at a nearby high school. Now someone with a gun sits all day to block our path. Sadly, more than one popular beach became fenced and guarded during this period.

Perhaps even more unbelievable to many of us was the sale of Botany Bay. This was formerly the largest tract of undeveloped land on St. Thomas, and home to some of the rarest plants and richest marine life. The property consists of three beaches, hundreds of acres, ruins of former plantations, and a slave cemetery. It was a cultural and environmental treasure and should have been a tourist attraction and cornerstone of our territorial park system. But we did not have a local park system. There was a strong federal park presence on the island of St. John - thanks to the now-deceased Laurance Rockefeller-and a lesser extent on St. Croix. There are a few beaches and recreation areas managed by the local government, but no park system and certainly no mechanism in place for purchasing and protecting land such as Botany Bay. We lost the fight for Botany Bay. I took great exception when that initiative was brought to the floor because I felt that there were other areas that were more suitable for major development. The land was rezoned and it sickens me to think that as I speak here today, it is being subdivided and roads cut through nearly every inch of that property.

\section{Solutions for the Future: Trying to Implement the Virgin Islands Territorial Park Trust Fund \& Virgin Islands Territorial Park Trust Fund Board}

By law, all Virgin Islands beaches are public. Virgin Islands beaches are public by way of an initiative now adopted into law - the Free Beach Access law-but only the beach. The confusion lies in the law. Technically, residents can visit the beaches at Botany Bay, or any place else any time they want, as long as they travel by boat, not by land. It was events such as these that made me more convinced than ever that what the Virgin Islands needed most was a system to protect land for the purpose of both recreation and conservation. If we were to have anything left for our children and grandchildren, we needed to act quickly to begin working towards purchasing these properties, which is something that I had already embarked on. It seems that with each passing week, we hear about another beach that was being closed to locals or another serious case of erosion due to poor building practices close to the sea.

My staff and I have worked diligently throughout my tenure on relatively simple legislation for setting up what I called the Virgin 
Islands Territorial Park Trust Fund and the Virgin Islands Territorial Park Trust Fund Board. This legislation, known as Act Number 6634, was to establish the framework for a territory-wide park system. The Board would be semi-autonomous and not subject to the whims of any governor or any official. In fact, the bill included language prohibiting the citizen-representatives from being government employees, so they would not be unduly influenced. I truly believe that parks are essential in protecting our quality of life and maintaining the Virgin Islands' desirability as a destination and, in particular, a tourist destination. When you ask those who visit the Virgin Islands what they like most about the Virgin Islands, they would certainly tell you that it poses a different ambiance and they come here for something totally different from the typical state-side structure. It is a getaway. I believe in order for us to market a package of the Virgin Islands effectively, it is most important that we protect the beauty of the islands. My colleagues supported me on this measure in early 2005 and even placed four million dollars in the fund towards the purchase of one beach that was up for development. This legislation creates a five-person board to oversee the acquisition of land and to accept donations of money and property. It was critical that the local power system not just be able to manage properties, but also acquire them through purchase and gifts. People who are donating parkland want to be sure that it is left in good, responsible hands, and the board was to act as trustees to make sure that properties remain in perpetuity. I envision this board making recommendations to the administration and the legislature about possible parkland and setting up advisory committees to establish rules and regulations for our parks, in addition to creating comprehensive management plans for the public beaches and parks we now have.

I do not think I have to tell those of you assembled here today about the environmental and economic benefits of protecting our natural resources, particularly in a place like the Virgin Islands. I consider this legislation an investment in our health, well-being, and in our tourism power. More parks would make us a better destination. Parks also create, rather than limit, jobs, which is a common misperception. In fact, I was placed in a position as a legislator to balance economic development, which would include jobs, versus the protection of our environment. One could easily assume that I would venture to go to the side of major development because of my business background. But it is because of my love for the Virgin Islands, that I recognize where we were and where we are now and see that the quality of the air is being affected. We talk about global warming, we talk about climate change, we talk about all the contaminants released into our air from heavy 
industry, but we do not really talk about what we are going to do to change it or address it. I do not think that my pursuit in the Virgin Islands, as it relates to major pieces of environmental legislation, was not appreciated. I think it was appreciated by virtue of my being elected as the number one vote-getter five consecutive terms in the Virgin Islands - with the exception of running for Governor, and I knew what my pitfalls were.

You would think that everyone wins with a territorial park system, but despite the law being in place, the then-Governor failed to appoint any individuals to serve on the Territorial Park Trust Fund Board. I lobbied hard. I wrote letter after letter. I sent the Governor a list of names and resumes of individuals who would qualify to serve on this Board. I worked for the support of my colleagues and pleaded my case for parks in front of the media and anyone else who would listen. Too many years have gone by and many valuable properties lost, and not a single individual has been appointed to serve on this Board. It was three names that the former Governor needed to send down, as two seats automatically belonged to commissioners in the Governor's cabinet. I still cannot tell you why the Governor failed to act on this. We lost numerous opportunities and continue to lose them while property values continue to rise and become more out of our reach. And we cannot forget that the Virgin Islands is made up of hundreds of small cays, many of which are subject to possible development if we do not find a mechanism to protect them. Many people believe that the Governor did not implement this legislation-or I would say administer or carry out the mandate - in order to resist giving me political credit for this political endeavor. I am not sure if it was apathy, greed, or politics that stopped him from moving forward, but we all have lost as a result of his failure to get the ball rolling on the park system.

When I ran for Governor last year, I campaigned hard, extremely hard, and I was quite emphatic on the issue of the need for a territorial park system. I would be the Governor to move this forward. Because of our growing concerns about loss of access and overdevelopment, one of our campaign slogans became "our beaches are not for sale." I was not successful in my bid to be Governor, obviously, as I was introduced here as Senator of the U.S. Virgin Islands. But I was highly successful in brining environmental issues into the debate. No other candidate campaigned on these issues, despite the public's increasing concern and awareness. I am sorry to say that after going on eleven months in office, the new Governor has not appointed anyone to the Territorial Park System Trust Fund Board. But thanks to my gubernatorial campaign, he is very well aware of the need to do so. I know that another Senator now 
in office has written to him and asked that he comply with the law in regard to appointing individuals to sit on this board, but he has failed to act. Meanwhile we are losing opportunities daily, in terms of possible land acquisitions. Our current parks are also in dire need of improved management. I truly believe that the surge of development must be mitigated by the permanent protection of beaches and green space. I can think of few issues as pressing at this time.

I am sorry to say that the idea of the territorial park system is going nowhere fast. Though I am not actively involved in public service at this time, I am looking at possible methods in which the chief executive could be induced to move forward. The Virgin Islands is certainly one of the most beautiful places in the entire world and incredibly rich in history and culture. But today, we must fight to protect our national heritage. We have lost so much already, and there is still so much to lose.

\section{CONCLUSION}

I wanted to once again thank you all for affording me this wonderful opportunity to present my experiences working with environmental issues in the United States Virgin Islands. The Virgin Islands is extremely dear to me. When we talk about biodiversity, I do not think that the average person truly recognized ten years ago what protecting natural resources does for the quality of your air, the quality of your water, and your quality of life in general. I felt that it was necessary for someone to step up to the plate and challenge the government and conventional wisdom in order to get others to recognize that there are environmentally sound and environmentally friendly developments out there that can in fact be embraced by all Virgin Islanders.

I must admit to you that when I was first elected to public office, the biggest challenge was getting my colleagues to understand biodiversity, to embrace various different concepts, and to become interested in learning about these areas. That was in fact my biggest challenge. Of course, the second biggest challenge was to get the realtors and all the major developers to understand that this was not a piece of antidevelopment legislation. Rather, it was a piece of legislation seeking to force, or bring us on, neutral ground, whereby the developers, the realtors, and the environmentalists would sit at the same table and share a common goal.

The Virgin Islands is not lost. We have the island of St. Croix and the island of St. John, each of which has a lot of green space remaininggreen space that we intend to protect. I am in fact the instrumental person in bringing to our shores two major developments for the island 
of St. Croix. First, we are going to construct in the U.S. territory a major shrimp and tilapia plant with forty franchise restaurants to be established throughout the United States. Second, we are bringing an environmentally friendly, 350-room hotel and casino that will be erected on the island of St. Croix. I felt that it was necessary, with my background, for me to get involved in these areas to make sure that the wrong thing was not done as they embarked on developing the island of St. Croix, or anywhere else.

It is really interesting coming from one arena to the next. As legislators and elected officials, we often hear "those guys," the "institution" called the Senate, or the "institution" called Congress. For those of us who may also fall on another side of the issue, we still have to accept and prepare to respond as an institution, because you are in fact part of the institution. When they talk about the institution, you are the institution. So that is something that you cannot get away from. I have realized that, and now being in the private sector as a consultant as well, I must say that there are some serious advantages to being on the other side. But once you understand the legislative process and once you understand the government, at least you are in a position to proceed in a smooth transition - in a way that others may embrace exactly what your arguments are and what your position is.

So I wanted to thank you for having me here this afternoon. This is the first time I have actually been to Kansas, and I love your state. Kansas City is really nice. Last night, I sat and ate dinner with these distinguished, accomplished attorneys and professors, and the hospitality has been encouraging. I am reminded, again, of something Michael Jordan once said. When I go back home I'll tell the people of the Virgin Islands "I'm back," and hopefully in the near future I will in fact be elected Governor of the Virgin Islands. After all, I am encouraged by the many attempts of Abraham Lincoln, who I think was the one that ran for office twenty-six times. I do not intend to run twenty-six times, but that is in fact encouraging and gives credence to the old notion that if at first you fail, try again. Fail again, try again. I intend to succeed the next time around. Hopefully in the near future, I will return to Kansas to share my future experiences in the Virgin Islands.

I would like to especially thank Dr. Andrew Torrance, a Kansas Law Professor, because I know he was instrumental in bringing me here for this Biolaw symposium. He is a very dear friend of mine. He has been coming to the Virgin Islands for almost a decade. Actually, I am surprised that his West Indian accent has not started to come out on campus. He knows about the local food, he knows about the culture, and I think he has grasped a true understanding of the Virgin Islands. It is 
always enlightening and good for us to be able to host him in the Virgin Islands. In fact, his students have visited the Virgin Islands over the last eight years to witness our culture, but more so to look at the biodiversity and the pristine areas and natural resources that we have in the Virgin Islands.

Once again, I thank you all for having me here today.

\section{QUESTIONS \& ANSWERS}

Question 1: Have they considered a lawsuit to force the Governor to appoint people to the Board? With all these great young law students here, I'm sure they would volunteer on a pro-bono basis to figure out a way to bring an action.

Senator Donastorg: Thanks for asking that question. You know that is interesting because I have about five court cases pending right now, so I guess it would be number six. And the populace of the Virgin Islands would probably say: "There goes Senator Donastorg, again." However, we have considered filing suit. It is in fact a serious concern and if I have to force his hand, I will.

Question 2: Have scientists been on your side at all in trying to protect biodiversity in the Virgin Islands? Have you thought about getting some outside scientists to come and help make your arguments?

Senator Donastorg: Yes, I believe it was about six years ago I testified before the Louisiana Senate and I was recognized in a resolution for my many accomplishments in the Virgin Islands along environmental lines. I cannot remember the correct title for their department that deals with environmental issues, but they had formed a partnership with and would provide scientists to our government. The government just failed to invite the scientists to our shores and provide some type of assistance, but it certainly would have been something that I would pursue.

Question 3: From your talk, one could get the impression that part of what is at issue here is conflict over what is the best way to pursue economic development. You could take the strategy of those who you have been opposing as one strategy, which of course would put certain barriers to access on the local people. But then you could also take tourism, the strategy that you certainly seem to favor, to be another one. Have there been any attempts to bring in economists, not scientists, in order show that in the long run, economic development will be best 
secured by the kind of plan that you're proposing, rather than what the status quo happens to be?

Senator Donastorg: Well, we have several economists that came to our shores. Most of the economists said that when you look at the landscape of the Virgin Islands, the infrastructure, it is obvious that you cannot grow anywhere beyond the shores, and that is why I was talking about environmentally-friendly projects, even for the island of St. Croix that has a lot of open space. Let us say, God forbid, a hurricane hits again and devastates the Virgin Islands. The economy is tourism, and tourists are definitely not going to visit a destination that has been totally ravaged. So what do you have to rely on, because you rely on one thing? The U.S. Virgin Islands are quite dependent on the federal government, FEMA, for assistance to keep us afloat until we can get our infrastructure back to what it used to be. What I have suggested to them is that we start looking at these parks and these areas where we can in fact expand our economy, because the tourism product is not going to work for us, especially when Cuba opens up the door. If they do, it is another destination that we have to compete with. I believe it is going to definitely adversely affect our tourism product and a number of people that visit our shores.

Question 4: Is there any cooperation between the U.S. and the British Virgin Islands when you have a major event happen like the hurricane? In addition to that, do they have a park system there that you can look at as sort of a model?

Senator Donastorg: Well, the British Virgin Islands do not have any territorial park systems whatsoever. There is in fact a relationship between the British Virgin Islands and the U.S. Virgin Islands. After any major disaster, any assistance that is afforded to the British Virgin Islands would probably come in the form of a partnership for the purpose of providing them needed assistance. But the British Virgin Islands have a structure in place now. In fact, unlike the U.S. Virgin Islands and unlike the United States, they have a serious surplus. We have what you call the EDC program that provides a tax shelter for companies that want to do business in the Virgins Islands, provided you qualify. They have what you call the IBC, International Business Companies, which is in fact a tax shelter with less restriction. Because the United States Congress closed some loopholes, it affected companies that were doing business in the Virgin Islands. They felt that the federal government would want to scrutinize everything, every activity that was going to take 
place, so they started to ship their operations slightly to the British Virgin Islands. Now, I'll give you an example when we talk about revenues generated. The British Virgin Islands has over 300,000 IBC companies, each company paying an average of about $\$ 5,000$ for bookkeeping and other services that they offer under that tax shelter. Now multiply that for a population that consists of probably only thirty-something thousand people. Our EDC program is only about sixty-eight companies. Those sixty-eight companies with the tax shelter file some income taxes. They get ninety-percent tax exemption but are required to pay the ten-percent along with employment. That is why, when we talk about economic activity in the Virgin Islands, boosting our economy is to provide employment. Now if I may switch over slightly, and I think I answered your question, you come back to putting a balance between economic development and the environmentalists. I feel that park rangers, scientists, and all these people that would work in the park system are handsomely paid. Those are good professions so those are good opportunities for young people, for anyone to pursue, should we develop a territorial park system. So those are jobs that will increase as well. It is necessary to convince the other side that there are job opportunities, and it will stimulate the economy and provide additional employment. But the British Virgin Islands will not need help from us. They are doing well. They have a serious surplus. After all, their legislators can increase their salaries by fifty-percent and no one squawks about it. In the U.S. Virgin Islands, they increase their salaries by $\$ 10,000$ and quite a number of them are going home.

Question 5: There is a park preservation strategy from your other neighbor, Vieques, probably the best biodiversity reserve in the eastern Caribbean. It is comparable to another area preserved in a similar way, Korea's demilitarized zone, which of course, if anyone knows, is the most militarized on earth. So, it turns out that things like landmines and bombs are affirmatively good for the environment. Leaving that aside, not saying that the U.S. Virgin Islands should volunteer to be a bombing range, would there be a strategy of setting aside certain portions of a landmass of the Virgin Islands completely from development, on a Vieques-like model?

Senator Donastorg: Well, it is difficult in the U.S. Virgin Islands. I will share with you the politics of it. There was a package or a draft that we created by a popular plan in natural resources, which was a proposal to the senate to adopt as legislation. It was called the Comprehensive Land and Water Use Plan. Within this plan, there was a section intended 
to separate certain parts of the Virgin Islands to ensure that specific areas were set aside for preservation, conservation, and protection. However, politics played a major role. Of course, once again, the realtors and the major developers decided that they do not want that legislation because it would have adversely affected their business. So they lobbied strong against it and were able to convince one particular Senator to submit the draft and request for that legislation. If you understand parliamentary procedure, that was a way of blocking the legislation for everything that they do not like. They submitted a request to legal counsel, so they automatically became the author and had the rights to that piece of legislation but requested that the legal counsel deem it not necessary at this time to bring it to the floor. It remains in legal counsel, languishing. Every time there was a new legislature, there was a network in place and someone was influenced to submit that draft and request to make sure that the legislation never made its way to the floor. So politics stopped it from ever coming to the floor when that happened. 